\title{
ROCK WREN NEST AT LAKE DIEFENBAKER, SASKATCHEWAN
}

MARTIN K. MCNICHOLL, 128 Silvergrove Hill N.W., Calgary, Alberta T3B $4 Z 5$.

On 4 July 1980, I was approaching the eastern edge of the Qu'Appelle Dam on the Gordon McKenzie Arm of Lake Diefenbaker, when I heard a song which was only vaguely familiar. As I started to cross the dam, I saw a wren singing on top of a large boulder, and realized that the bird was a Rock Wren, a species with which I have had only a few previous encounters. Before I could confirm my tentative identification, the bird flew down among the rocks out of sight, but a few minutes later another wren sang close to me, and I was able to confirm the identification. I continued across the dam to the beach off the western edge, but on my return about one hour later, heard the song again and decided to attempt to photograph the bird. As I approached, I noticed that it was carrying food in its bill, and then saw a second bird, also with food. I sat down on a large boulder and watched the two agitated birds. It soon became clear that I was sitting close to a nest, as both birds approached repeatedly, and several times darted among nearby rocks. Finally, one disappeared under some rocks only about $1 \mathrm{~m}$ away from me, and I heard the distinct sounds of begging young. Investigation revealed a nest under the bank of the road on top of the dam at the end of a passage about $36 \mathrm{~cm}$ through rocks. I was barely able to squeeze my hand to the edge of the nest, and managed to pull out a nestling. The young bird had its eyes open, but was feeble and only the primaries showed signs of developing. These were still at the "pin feather" stage, showing no sign of opening. After photographing the nestling (Fig. 1), I replaced it. I could not reach any other young, but at least two could be heard

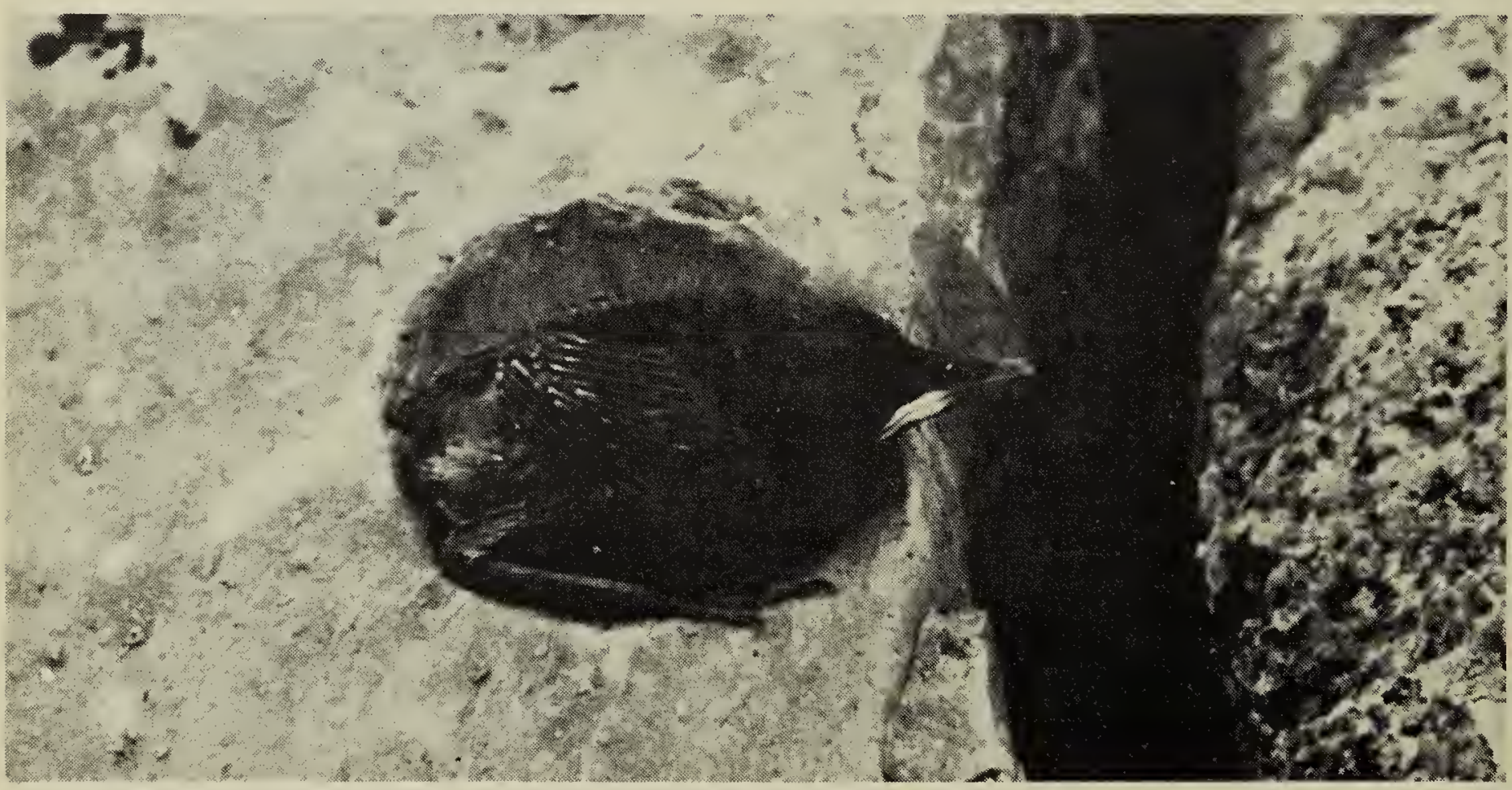

Figure 1. Rock Wren nestling. 
